\title{
Atributos físicos do solo cultivado com cana-de-açúcar em função do preparo e época de amostragem
}

\author{
Sálvio Napoleão Soares Arcoverde ${ }^{1}$, Cristiano Márcio Alves de Souza ${ }^{1}$, Andres Hideki Tanaka \\ Suarez $^{1}$, Bruno Agostini Colman ${ }^{1}$, Hideo de Jesus Nagahama ${ }^{2}$
}

\begin{abstract}
${ }^{1}$ Universidade Federal da Grande Dourados, Dourados, Mato Grosso do Sul, Brasil. E-mail: salvionapoleao@gmail.com, csouza@ufgd.edu.br, hideki_04@hotmail.com, brunoagostini@hotmail.com
\end{abstract}

${ }^{2}$ Universidade Federal do Vale do São Francisco, Juazeiro, Bahia, Brasil. E-mail: hideo.agro@ gmail.com

Recebido: 16/06/2018; Aceito: 22/01/2019.

\begin{abstract}
RESUMO
Objetivou-se avaliar os atributos físicos de um Latossolo Vermelho Distroférrico cultivado com cana-planta em função do preparo e época de amostragem. O trabalho foi conduzido na FAECA-UFGD, em um Latossolo Vermelho Distroférrico, onde a área experimental foi dividida em duas subáreas, compostas pelo sistema plantio direto (SPD) e preparo reduzido (PR). Em cada tipo de preparo foram cultivadas oito cultivares de cana-de-açúcar em delineamento inteiramente casualizado, com quatro repetições. Nas unidades experimentais, amostras com estrutura preservada foram coletadas após o preparo do solo (45 DAP) e após os tratos culturais (180 DAP), para determinação da densidade do solo, porosidade total, macroporosidade, microporosidade e resistência mecânica do solo à penetração nas camadas de 0,00-0,10 e 0,10-0,20 m. O SPD apresentou maior densidade e resistência do solo à penetração na camada de 0,00-0,10 m, enquanto os demais atributos físicos não foram influenciados pelo preparo do solo. Houve aumento da densidade do solo, porosidade total, microporosidade e resistência do solo à penetração e diminuição da macroporosidade nas camadas de 0,00-0,10 e 0,10-0,20 m após o tráfego de máquinas para tratos culturais.
\end{abstract}

Palavras-chave: Saccharum spp., compactação do solo, plantio direto, preparo reduzido.

\section{Soil physical attributes cultivated with sugarcane affected by tillage and sampling time}

\begin{abstract}
The objective of this study was to evaluate the physical attributes of a Dystroferric Red Latosol cultivated with cane-plant in function of the preparation and time of sampling. The work was conducted at FAECA-UFGD where the experimental area was divided into two subareas, composed by no-tillage (SPD) and reduced tillage (PR). Eight sugarcane cultivars were cultivated in each preparation in a completely randomized design, with four replications. In the experimental units, samples with preserved structure were collected after soil preparation (45 DAP) and after the cultural treatments (180 DAP), to determine soil density (Ds), total porosity (Pt), macroporosity (Ma), microporosity (Mi) and soil mechanical resistance to penetration (RP) in the layers of 0.00 0.10 and $0.10-0.20 \mathrm{~m}$ depth. The SPD presented higher density and resistance of the soil to the penetration in the layer of $0.00-0.10 \mathrm{~m}$, while the other attributes physical did not suffer influence of the preparation of the soil. There was an increase in soil density, total porosity, microporosity and soil resistance to penetration and decrease of macroporosity after the machinal traffic of cultural treatments in the layers of $0.00-0.10$ and $0.10-0.20 \mathrm{~m}$.
\end{abstract}

Keywords: Saccharum spp., soil compaction, no-tillage, reduced tillage. 


\section{Introdução}

A cana-de-açúcar é uma das culturas de maior importância no agronegócio brasileiro, visto que apresenta elevado potencial para diversos usos na agroindústria e na cogeração de energia elétrica. $\mathrm{O}$ aumento da demanda por produtos derivados da canade-açúcar é responsável pelo crescimento do setor sucroenergético brasileiro, o que resulta na expansão dos canaviais e investimentos na construção de novas usinas, sobretudo na região Centro-sul.

O sistema de produção da cana-de-açúcar envolve o uso de máquinas agrícolas em diferentes etapas, desde o preparo do solo até a colheita da matéria-prima (Baquero et al., 2012). Sendo, portanto, um sistema produtivo que requer intensa mecanização agrícola altamente tecnificada em todo o ciclo da cultura, com máquinas modernas e versáteis que executem trabalhos com máxima eficiência e baixo custo, a fim de destinar matéria-prima de qualidade à agroindústria (Souza et al., 2012).

As sucessivas operações mecanizadas - do preparo do solo até a colheita, resultam em problemas de degradação do solo, sendo o principal a compactação (Silva e Castro 2015; Marasca et al., 2015; Vischi Filho et al., 2015), que pode afetar a produção e a longevidade do canavial (Camilotti et al., 2005; Fagundes et al., 2014), bem como a área explorada pelo sistema radicular (Baquero et al., 2012; Marasca et al., 2015).

O preparo do solo, se executado em condições de teor de água do solo na faixa de friabilidade, proporciona melhorias nas funções do solo como aeração, disponibilidade e retenção de água e nutrientes e estrutura, envolvidas no crescimento e desenvolvimento radicular (Valadão et al., 2015). Logo, na cultura da cana-de-açúcar, esta operação é crucial já que é realizada apenas no momento do plantio e renovação do canavial (Carvalho et al., 2011).

No entanto, no sistema de preparo convencional, a sequência de operações com implementos, como arados e grades, promove a compactação e afeta a estrutura do solo, com alteração de atributos físicos do solo (Camilotti et al., 2005; Carvalho et al., 2011; Marasca et al., 2015). Havendo assim, geralmente redução da qualidade do solo nos sistemas em que ocorre mobilização deste, devido às modificações ocasionadas nos atributos físicos, como aumento da densidade do solo e resistência do solo à penetração (Laurindo et al., 2009; Marasca et al., 2015; Silva e Castro, 2015).

As ferramentas de preparo do solo em sistema convencional modificam a estrutura do solo, com transformação da camada arável em superfície pulverizada e a subsuperficial compactada. Porém, no SPD, a semeadura é feita sem o preparo do solo e os restos culturais são mantidos na superfície, sendo um sistema mais eficaz na proteção do solo contra agentes erosivos (Kamimura et al., 2009). Apesar dos benefícios, há necessidade de informações acerca dos impactos da adoção de tais sistemas de manejo do solo, tanto ocasional como a longo prazo, a fim de estabelecer relação entre os efeitos da compactação, com os atributos físicos do solo e o desenvolvimento da cultura.

O fato de não haver revolvimento do solo em SPD pode acarretar aumento dos valores da densidade e resistência mecânica do solo à penetração em camadas subsuperficiais (Carvalho et al., 2011). No entanto, tais atributos se comportam de forma dinâmica em função do solo, das condições de manejo e ao longo do tempo, havendo, portanto, necessidade de acompanhamento imediato e ao longo dos anos (Laurindo et al., 2009).

Neste contexto, objetivou-se avaliar os atributos físicos de um Latossolo Vermelho Distroférrico cultivado com cana-planta em função do tipo de preparo e época de amostragem.

\section{Material e Métodos}

O experimento foi conduzido no ano agrícola 2016/2017, no município de Dourados, região Sul do Mato Grosso do Sul, cujas coordenadas geográficas são: $22^{\circ} 13^{\prime} 58^{\prime}$ ' Sul e $54^{\circ} 59^{\prime}$ '57" oeste e altitude de $418 \mathrm{~m}$. O clima da região é do tipo Am, monçônico, com inverno seco, e precipitação média anual de $1500 \mathrm{~mm}$, e temperatura média anual de $22^{\circ} \mathrm{C}$ (Alvares et al., 2013).

O solo da área é classificado como Latossolo Vermelho distroférrico, textura argilosa, tendo na camada de 0,00-0,10 m $597 \mathrm{~g} \mathrm{~kg}^{-1}$ de argila, $151 \mathrm{~g} \mathrm{~kg}^{-1}$ de silte e $252 \mathrm{~g} \mathrm{~kg}^{-1}$ de areia; e na camada de $0,10-0,20$ m $602 \mathrm{~g} \mathrm{~kg}^{-1}$ de argila, $157 \mathrm{~g} \mathrm{~kg}^{-1}$ de silte e $241 \mathrm{~g} \mathrm{~kg}^{-1} \mathrm{de}$ areia.

A área destinada ao experimento, que estava há 14 anos sob cultivo de soja e milho, em um sistema de sucessão e rotação de culturas sem revolvimento do solo, apresentava homogeneidade das condições ambientais e do material experimental, localizada em topografia plana, sem variação do tipo de solo e técnicas de manejo. A mesma foi dividida em duas subáreas, compostas pelo sistema plantio direto (SPD) e preparo reduzido. Em cada preparo, realizou-se o plantio manual das cultivares de cana-de-açúcar no dia 21 de julho de 2016, considerando a densidade de 15 gemas por metro.

Foram cultivadas oito cultivares de cana-de-açúcar (RB965902， RB985476, RB966928, RB855156, RB975201, RB975242, RB036066 e RB855536) em delineamento inteiramente casualizado, com quatro repetições. Cada unidade experimental continha 5 linhas de cana com 5 metros de comprimento, espaçadas de $1,50 \mathrm{~m}\left(37,5 \mathrm{~m}^{2}\right)$, num total de 32 unidades experimentais por preparo (repetições).

$\mathrm{O}$ delineamento experimental foi inteiramente casualizado, em esquema fatorial $2 \times 2$, sendo dois 
sistemas de preparo do solo (SPD e PR) e duas épocas de amostragem (após o preparo do solo e após tratos culturais), e 32 repetições.

$\mathrm{O}$ preparo reduzido (PR) consistiu de gradagem pesada, enquanto o SPD consistiu de trituração de plantas daninhas, e posteriormente, abertura de sulcos com mobilização do solo apenas na linha de plantio.

Para as operações de preparo e sulcação, foi utilizado o trator 4x2 New Holland, modelo 8030 de potência no motor de $89,79 \mathrm{~kW}(122 \mathrm{cv})$, rotação de $2200 \mathrm{rpm}, 3^{\mathrm{a}}$ marcha reduzida, pneus dianteiros 14,9-58 e traseiros 23,1-30, e massa de 4,51 Mg. Para a cobertura dos sulcos e tratamento fitossanitário, foi utilizado o trator 4x2 TDA Massey Fergusson, modelo MF292 de potência no motor $68,74 \mathrm{~kW}(92 \mathrm{cv})$, rotação de $2200 \mathrm{rpm}, 3^{\mathrm{a}}$ marcha reduzida, pneus dianteiros 7,5018 e traseiros 18,4-34, e massa de 3,40 Mg; e pulverizador KO Cross-s 2000, pneus 9,5-24, $14 \mathrm{~m}$ de barra e massa de $1,4 \mathrm{Mg}$.

Para o preparo do solo, foram utilizados: triturador de palhas equipado com rotor de facas curvas de aço que trabalham em alta rotação e massa de $1,2 \mathrm{Mg}$, montado em um trator sulcador de duas linhas; e grade aradora, tipo off-set, de arrasto, com 16 discos de 0,76 $\mathrm{m}$ de diâmetro (30") em cada seção, que atuaram até $0,15 \mathrm{~m}$, com massa de $2,0 \mathrm{Mg}$.

Nos dias 16 de setembro e 02 de outubro de 2016 efetuou-se o controle químico das plantas daninhas no experimento, com aplicação de pré-emergente e pósemergente, respectivamente.

A formulação do Tebuthiuron utilizada foi Combine $^{\circledR} 500$ SC suspensão concentrada (500 g i.a. L${ }^{1}$ ), aplicada na dose de $2,4 \mathrm{~L} \mathrm{ha}^{-1}$. A formulação do haloxyfop-methyl foi Verdict-R®, aplicada na dose de $0,5 \mathrm{~L} \mathrm{ha}^{-1}$.

Em 12 de setembro de 2016 e 04 de fevereiro de 2017, na área útil de cada unidade experimental foram coletadas amostras de solo com estrutura preservada, em três pontos na entrelinha da cana-de-açúcar nas camadas de 0,00-0,10 e 0,10-0,20 m. Para tanto, utilizaram-se anéis volumétricos $(0,0557 \mathrm{~m}$ de diâmetro e $0,0441 \mathrm{~m}$ de altura), que em seguida foram envolvidos em papel filme e acondicionados em geladeira, visando o mínimo de alteração estrutural e perda de água.

A avaliação dos atributos físicos densidade do solo, porosidade total, macroporosidade e microporosidade, foi feita de acordo com Camargo et al. (1986). A densidade do solo foi determinada pela massa de solo seco em estufa a $105-110^{\circ} \mathrm{C}$, sendo os valores expressos em $\mathrm{kg} \mathrm{dm}^{-3}$.

A porosidade total foi determinada pela quantidade de água do solo saturado; e a microporosidade, pela água retida a uma tensão de $6 \mathrm{kPa}$, sendo os valores expressos em $\mathrm{m}^{3} \mathrm{~m}^{-3}$. A macroporosidade é a diferença entre a porosidade total e microporosidade.
Ao atingir o equilíbrio na tensão correspondente a coluna de água de $6 \mathrm{kPa}$, a RP foi determinada, por meio de penetrógrafo eletrônico modelo MA-933, com velocidade constante de penetração de $10 \mathrm{~mm} \mathrm{~min}^{-1}$, diâmetro de base da haste de $4 \mathrm{~mm}$ e ponta cônica angular a $30^{\circ}$, conforme padronização pela ASABE (ASABE, 2006). As amostras obtidas nos $5 \mathrm{~mm}$ superiores e inferiores da amostra foram descartadas, visando eliminar o efeito da periferia da amostra. A frequência de leituras de RP correspondeu à coleta de um valor a cada $0,25 \mathrm{~s}$, obtendo-se 800 leituras por amostra, sendo utilizado o valor médio, conforme Bergamin et al. (2010).

Os dados dos atributos físicos do solo foram submetidos à análise de variância, sendo as médias comparadas pelo teste SNK, a $5 \%$ de probabilidade.

\section{Resultados e Discussão}

Observou-se significância para interação entre os preparos e as épocas de amostragem para microporosidade $(\mathrm{Mi})$ e resistência mecânica do solo à penetração (RP), na camada de 0,00-0,10 m, e para porosidade total $(\mathrm{Pt})$, microporosidade $(\mathrm{Mi}) \mathrm{e}$ macroporosidade (Ma), na camada de 0,10-0,20 m (Tabela 1). Houve influência da época de amostragem (E) para todos os atributos físicos estudados nas camadas de 0,00-0,10 e 0,10-0,20 m de profundidade. Não houve influência do preparo do solo (P) para os atributos físicos em ambas as camadas de solo, exceto para densidade do solo (Ds) na camada de 0,00-0,10 m, que apresentou maior valor em SPD (Figura 1).

Na Figura 1 observa-se que maiores valores de Ds são encontrados no SPD na camada superficial $(0,00$ $0,10 \mathrm{~m}$ ), o que pode ser atribuído ao não revolvimento do solo nesta área. Ralisch et al. (2008) destacam que a implantação ocasional do SPD pode resultar em compactação do solo. Já Laurindo et al. (2009), estudando os efeitos de manejos conservacionistas do solo nos atributos físicos, destacam que o revolvimento do solo no cultivo mínimo é responsável por reduzir a Ds. Contudo, ao analisar a camada de $0,10-0,20 \mathrm{~m}$ os valores de Ds se igualaram entre os preparos, o que provavelmente ocorreu devido à ação da ferramenta de preparo que promoveu maior pressão nesta camada, ou segundo Viana et al. (2011), ao rearranjamento dos poros pós-preparo.

Ressalta-se que os valores de Ds obtidos nos sistemas de preparo do solo nas camadas de 0,00-0,10 e 0,10-0,20 m estão abaixo da faixa de 1,51 a $1,59 \mathrm{Mg} \mathrm{m}^{-3}$ considerados máximos por Sá et al. (2016) e Oliveira et al. (2012) ao avaliarem a compactação em Latossolos de textura argilosa a muito argilosa. Camargo e Alleoni (1997) consideraram crítico o valor de $1,55 \mathrm{Mg} \mathrm{m}^{-3} \mathrm{em}$ solos franco-argilosos a argilosos. 
Tabela 1. Resumo da análise de variância para os atributos físicos do solo nas camadas de 0,00-0,10 e 0,10-0,20 m, em função do preparo do solo e época de amostragem.

\begin{tabular}{|c|c|c|c|c|c|c|c|}
\hline \multirow{2}{*}{ Prof. (m) } & \multirow{2}{*}{ FV } & \multirow{2}{*}{ GL } & \multicolumn{5}{|c|}{ Quadrados médios } \\
\hline & & & Ds & $\mathrm{Pt}$ & $\mathrm{Ma}$ & $\mathrm{Mi}$ & $\mathrm{RP}$ \\
\hline & & & $\mathrm{kg} \mathrm{dm}^{-3}$ & \multicolumn{3}{|c|}{-----------------m³ m m $^{-3}$---------------- } & $\mathrm{MPa}$ \\
\hline \multirow{5}{*}{$0-0,10$} & $\mathrm{P}$ & 1 & $0,0886^{* *}$ & 29,5304 & 34,8168 & 0,2175 & 0,7078 \\
\hline & $\mathrm{E}$ & 1 & $0,5935 * *$ & $43,7401 *$ & $505,172 * *$ & $846,209 * *$ & $135,532 * *$ \\
\hline & $\mathrm{P} \times \mathrm{E}$ & 1 & 0,0036 & 3,7648 & 4,6026 & $16,69269^{*}$ & $10,1504 *$ \\
\hline & Res. & 124 & 0,0084 & 8,06884 & 8,9357 & 3,50607 & 2,5583 \\
\hline & \multicolumn{2}{|c|}{$\mathrm{CV}(\%)$} & 6,42 & 6,47 & 46,79 & 4,99 & 50,23 \\
\hline \multirow{5}{*}{$0-0,20$} & $\mathrm{P}$ & 1 & 0,0043 & 2,7119 & 12,1876 & 0,2175 & 1,1797 \\
\hline & $\mathrm{E}$ & 1 & $0,5008 * *$ & $188,370 * *$ & $50,1158 * *$ & $846,209 * *$ & $132,884 * *$ \\
\hline & $\mathrm{P} \times \mathrm{E}$ & 1 & 0,0035 & $36,8236^{*}$ & $25,9057^{*}$ & $16,6926^{*}$ & 1,6573 \\
\hline & Res. & 124 & 0,04899 & 5,8605 & 5,9177 & 3,5061 & 2,4050 \\
\hline & \multicolumn{2}{|c|}{$\mathrm{CV}(\%)$} & 14,90 & 5,59 & 43,18 & 4,99 & 48,06 \\
\hline
\end{tabular}

CV - Coeficiente de variação (\%); P: preparo do solo; E: época de amostragem; Trat.: tratamento; Res.: Resíduo; Ds: densidade do solo; Pt: porosidade total do solo; Ma: macroporosidade do solo; Mi: microporosidade do solo; RP: resistência mecânica do solo à penetração.

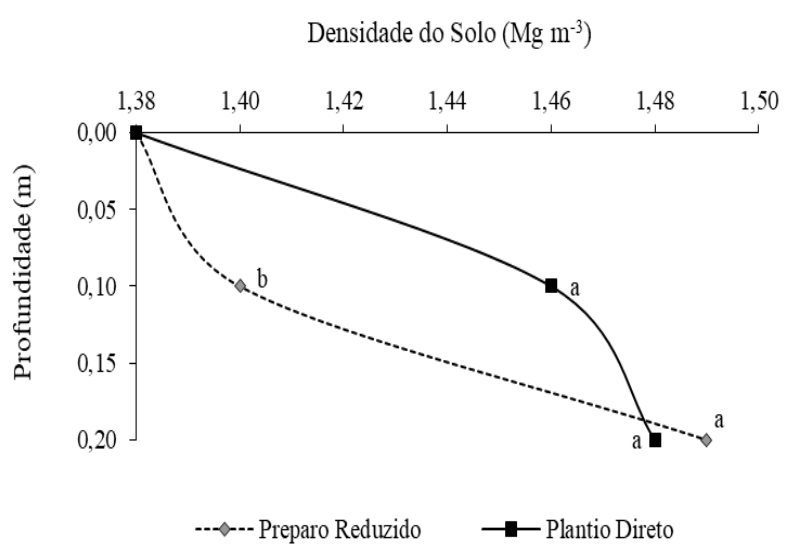

Figura 1. Valores médios de densidade do solo na camada de 0,00-0,10 m e 0,10-0,20 m de profundidade em função do preparo do solo. Dourados - MS, 2016/2017. Médias seguidas de mesma letra, não diferem entre si pelo teste SNK $(\mathrm{p}<0,05)$.

Baquero et al. (2012) estudando atributos físicos de um Latossolo Vermelho Eutroférrico, com porcentagem de argila superior a $65 \%$, destacaram que valores de $1,48 \mathrm{Mg} \mathrm{m}^{-3}$ indicam compactação, podendo restringir o crescimento e desenvolvimento da raiz, além de problemas agravantes de baixa infiltração de água e baixa aeração do solo. Assim, entende-se que nos sistemas estudados há tendência de compactação ao avaliar os valores de Ds na camada até 0,20 m de profundidade.

Ao analisar o desdobramento para $\mathrm{Mi}$ e RP na camada de 0,00-0,10 m de profundidade (Figura 2), observou-se incremento, tanto na Mi quanto na RP, da primeira para a segunda amostragem em ambos os preparos do solo. O aumento de RP se deve ao contínuo tráfego de tratores; sendo estes responsáveis por provocar compactação superficial (Bergamin et al., 2010); neste estudo ocorreu em razão da pressão exercida pelos rodados do trator nas operações de aplicação de produtos no controle químico de plantas espontâneas na cana-de-açúcar.

Analisando-se o desdobramento de Pt, Ma e Mi na camada de 0,10-0,20 m (Figura 3), observou-se, tanto em preparo reduzido quanto em SPD, aumento dos valores dos atributos da primeira para a segunda avaliação. Nesta profundidade também houve variação da Mi, em ambos os preparos do solo, com aumento da primeira para a segunda avaliação, assim como ocorreu na camada de 0,00-0,10 m (Figura 2). Ao longo do tempo, verificou-se aumento na $\mathrm{Pt}$ em preparo reduzido e SPD; isso pode ser explicado pela relação direta entre Pt e Ma, porém, tal relação não foi verificado em SPD, onde a maior Mi possivelmente influenciou a Pt.

Observando-se os valores médios dos atributos físicos nas camadas de 0,00-0,10 e 0,10-0,20 m, ao longo do tempo, verificou-se aumento de Ds, Pt, Mi e $\mathrm{RP}$, e redução de Ma (Tabela 2). Podem-se verificar baixos valores de Ma em ambos os sistemas, inferiores a $0,10 \mathrm{~m}^{3} \mathrm{~m}^{-3}$, mínimo adequado para as trocas líquidas e gasosas entre o ambiente externo e o solo, e considerado crítico para o crescimento das raízes na maioria das culturas como enfatizam Centurion et al. (2007) e Rossetti e Centurion (2013).

Araújo et al. (2013), ao avaliarem dois sistemas de colheita de cana-de-açúcar em um Latossolo Vermelho Distrófico sob preparo convencional, verificaram valores de Ma semelhantes nas camadas avaliadas, ou seja, inferiores a $0,10 \mathrm{~m}^{3} \mathrm{~m}^{-3}$; porém com valores de Mi acima de $0,40 \mathrm{~m}^{3} \mathrm{~m}^{-3}$, o que pode indicar maior compactação nesta área.

Os valores de RP após o manejo da cultura foram considerados altos, podendo representar limitação ao desenvolvimento radicular da cana-de-açúcar, visto que conforme Sá et al. (2016), tais valores são superiores a 3,8 $\mathrm{MPa}$. 


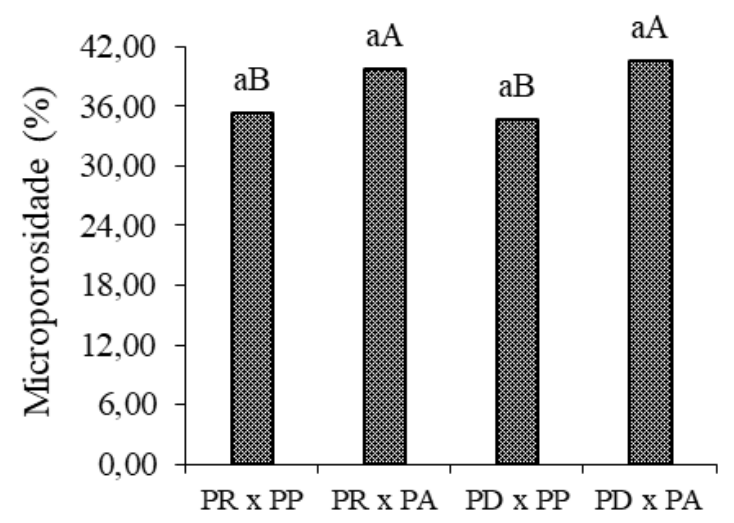

Sistemas de preparo do solo versus Épocas de amostragem

(A)

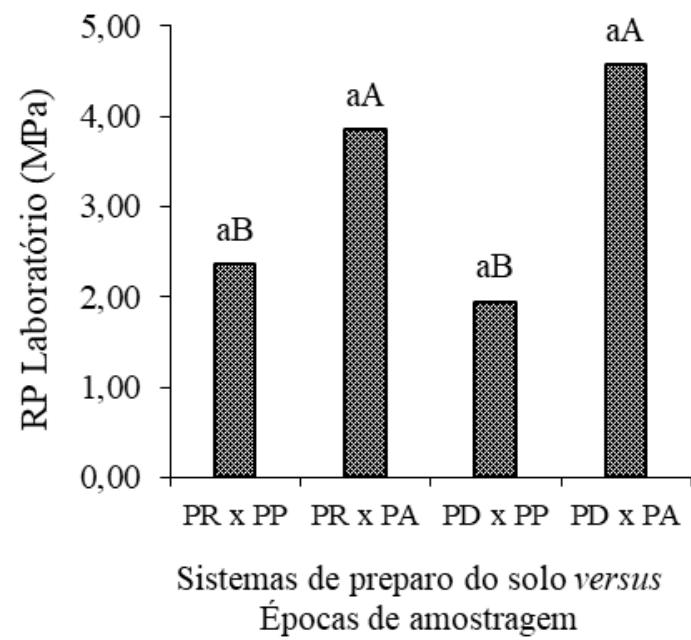

(B)

Figura 2. Valores médios do desdobramento de microporosidade (A) e resistência mecânica do solo à penetração (B) na camada de 0,00-0,10 m entre preparos do solo e épocas de amostragem. Dourados - MS, 2016/2017. Médias seguidas de mesma letra, maiúscula para efeito dos preparos do solo, minúscula para efeito das épocas de amostragem, não diferem entre si pelo teste $\mathrm{SNK}$ ( $\mathrm{p}<0,05$ ). PP: Pós - preparo do solo; PA: Pós - aplicação de produtos fitossanitários.

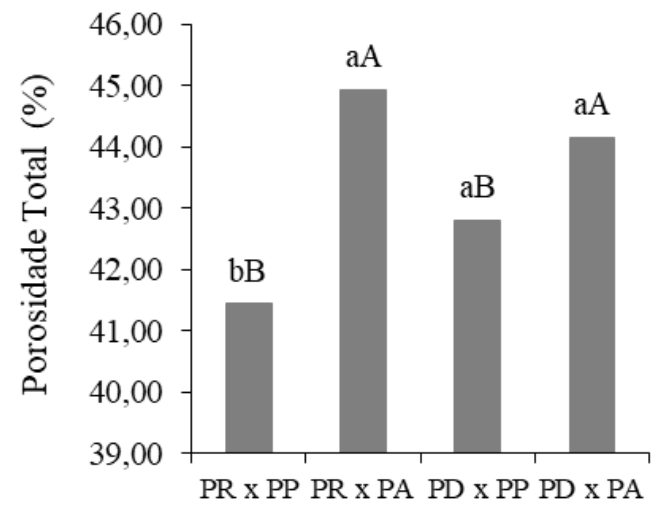

Sistemas de preparo do solo versus Épocas de amostragem

(A)

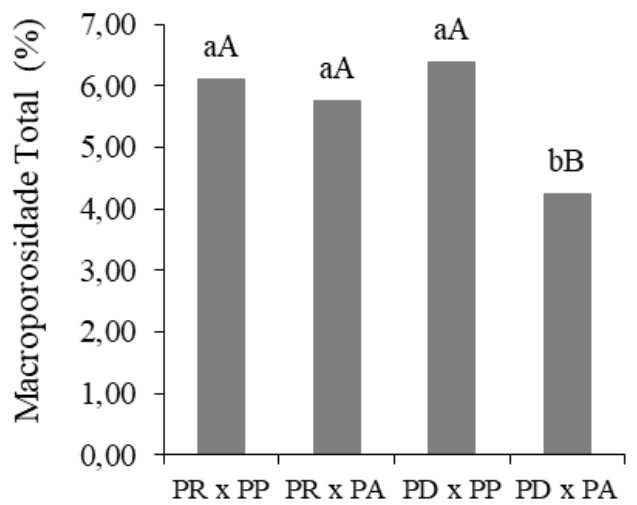

Sistemas de preparo do solo versus Épocas de amostragem

(B)

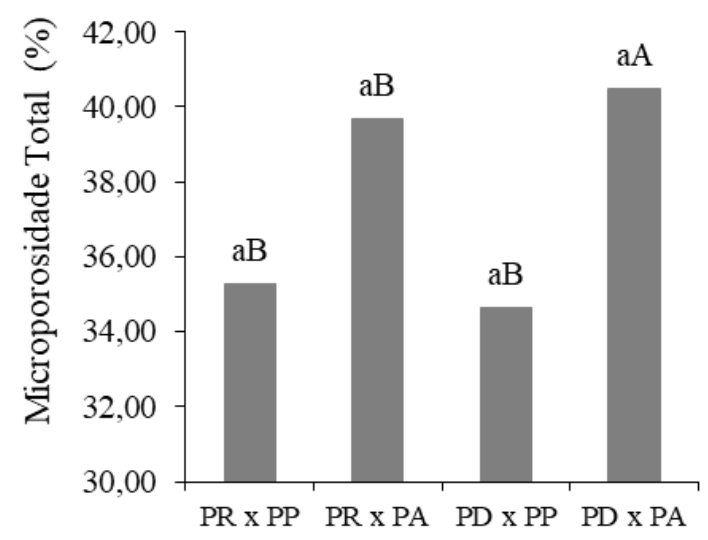

Sistemas de preparo do solo versus Épocas de amostragem

(C)

Figura 3. Valores médios do desdobramento de porosidade total do solo (A), macroporosidade (B) e microporosidade (C) na camada de 0,10-0,20 m entre preparos do solo e épocas de amostragem. Dourados - MS, 2016/2017. Médias seguidas de mesma letra, maiúscula para efeito dos preparos do solo, minúscula para efeito das épocas de amostragem, não diferem entre si pelo teste SNK (p<0,05). PP: Pós - preparo do solo; PA: Pós - aplicação de produtos fitossanitários. 
Tabela 2. Valores médios de densidade do solo (Ds), porosidade total do solo (Pt), macroporosidade (Ma), microporosidade (Mi) e resistência mecânica do solo à penetração (RP) nas camadas de 0,00-0,10 e 0,10-0,20 m, em função das épocas de amostragem (PP: Pós - preparo do solo; PA: Pós - aplicação de produtos fitossanitários.

\begin{tabular}{|c|c|c|c|c|c|}
\hline \multirow{2}{*}{$\begin{array}{c}\text { Época de } \\
\text { amostragem }\end{array}$} & Ds & $\mathrm{Pt}$ & Ma & Mi & $\mathrm{RP}$ \\
\hline & $\mathrm{Mg} \mathrm{m}^{-3}$ & \multicolumn{3}{|c|}{ 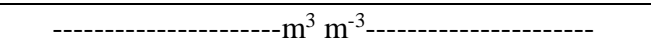 } & $\mathrm{MPa}$ \\
\hline & \multicolumn{5}{|c|}{$0,00-0,10 \mathrm{~m}$} \\
\hline PP & $1,36 \mathrm{~b}$ & $0,43 \mathrm{~b}$ & $0,08 \mathrm{a}$ & $0,35 \mathrm{~b}$ & $2,16 \mathrm{~b}$ \\
\hline \multirow[t]{2}{*}{$\mathrm{PA}$} & $1,50 \mathrm{a}$ & $0,44 \mathrm{a}$ & $0,04 \mathrm{~b}$ & $0,40 \mathrm{a}$ & $4,21 \mathrm{a}$ \\
\hline & \multicolumn{5}{|c|}{$0,10-0,20 \mathrm{~m}$} \\
\hline PP & $1,36 \mathrm{~b}$ & $0,42 \mathrm{~b}$ & $0,06 \mathrm{a}$ & $0,35 \mathrm{~b}$ & $2,21 \mathrm{~b}$ \\
\hline PA & $1,50 \mathrm{a}$ & $0,45 \mathrm{a}$ & $0,05 \mathrm{~b}$ & $0,40 \mathrm{a}$ & $4,24 \mathrm{a}$ \\
\hline
\end{tabular}

Médias seguidas de mesma letra, não diferem entre si pelo teste SNK $(\mathrm{p}<0,05)$.

Os valores verificados neste estudo diferiram das observações de Baquero et al. (2012), que, ao avaliarem um Latossolo Vermelho eutroférrico, de textura argilosa, sob preparo convencional, ao longo de vários ciclos de cana-de-açúcar, encontraram valores inferiores a 4,0 MPa na camada até $0,40 \mathrm{~m}$. No entanto, valores de RP entre 3,0 e 4,0 MPa são considerados críticos para outras culturas em SPD, como relatado por Betioli Júnior et al. (2012) e Guimarães et al. (2013).

Observou-se nas camadas de 0,00-0,10 e 0,10-0,20 $\mathrm{m}$ valores de Ds abaixo da faixa de 1,51 a $1,59 \mathrm{Mg} \mathrm{m}^{-3}$ considerados máximos por Sá et al. (2016) e Oliveira et al. (2012) ao avaliarem a compactação em Latossolos de textura argilosa a muito argilosa. Laurindo et al. (2009), em estudo realizado no oeste do Paraná, em um Nitossolo argiloso, verificaram valores médios de densidade de 1,29 e $1,28 \mathrm{Mg} \mathrm{m}^{-3}$ em plantio direto e preparo reduzido, na camada de 0,00-0,20 m de profundidade, valores muito inferiores aos obtidos neste estudo.

\section{Conclusões}

O sistema plantio direto apresentou maior densidade e resistência do solo à penetração na camada de 0,00 $0,10 \mathrm{~m}$, enquanto os demais atributos físicos não foram influenciados pelo preparo do solo.

Houve aumento da densidade do solo, porosidade total, microporosidade e resistência do solo à penetração e diminuição da macroporosidade nas camadas de 0,00 0,10 e 0,10-0,20 m após o tráfego de máquinas para tratos culturais.

\section{Agradecimentos}

À UFGD, CAPES, FINEP e FUNDECT, pelo apoio financeiro. À CAPES, pela concessão das bolsas de Doutorado e Pós-Doutorado ao primeiro autor. Ao CNPq, pela bolsa PQ concedida ao segundo autor.

\section{Referências Bibliográficas}

Alvares, C.A., Stape, J.L., Sentelhas, P.C., Gonçalves, J.L.M., Sparovek, G. 2013. Köppen's climate classification map for Brazil. Meteorologische Zeitschrift, 22, 711-728.

Araújo, F.S., Souza, Z.M., Souza, G.S., Matsura, E.E., Barbosa, R.S. 2013. Espacialização do intervalo hídrico ótimo de um Latossolo Vermelho em dois sistemas de colheita de cana-de-açúcar. Pesquisa Agropecuária Brasileira, 48, 651660.

ASABE. American Society of Agricultural and Biological Engineers. Soil cone penetrometer. Saint Joseph, 2006b. p.902-904. (ASABE standard: ASAE S313.3 FEB04).

Baquero, J.E., Ralisch, R., Conti, M., Tavares Filho, C., Guimarães, M. F. Soil physical properties and sugarcane root growth in a red oxisol. 2012. Revista Brasileira de Ciência do Solo, 36, 63-70.

Bergamin, A.C., Vitorino, A.C.T., Franchini, J.C., Souza, C M.A., Souza, F.R. 2010. Compactação de um Latossolo Vermelho Distroférrico e suas relações com o crescimento radicular do milho. Revista Brasileira de Ciência do Solo, 34, 681-691.

Betioli Júnior, E., Moreira, W.H., Tormena, C.A., Ferreira, C.J.B., Silva, A.P., Giarola, N.F.B. 2012. Intervalo hídrico ótimo e grau de compactação de um Latossolo Vermelho após 30 anos sob plantio direto. Revista Brasileira de Ciência do Solo, 36, 971-982.

Camargo, O.A., Alleoni, L.R.F. 1997. Compactação do solo e o desenvolvimento das plantas, Escola Superior de Agricultura Luiz de Queiroz, Piracicaba.

Camargo, O.A., Moniz, A.C., Jorge, J.A., Valadares, J.M.A.S. 1986. Métodos de análise química, mineralógica e física de solos do Instituto Agronômico de Campinas, Instituto Agronômico de Campinas, Campinas.

Camilotti, F., Andrioli, I., Dias, F.L.F., Casagrande, A.A., Silva, A.R., Mutton, M., Centurion, J.F. 2005. Efeito prolongado de sistemas de preparo do solo com e sem cultivo de soqueira de cana crua em algumas propriedades físicas do solo. Engenharia Agrícola, 25, 189-98. 
Carvalho, L.A., Silva Junior, A.A., Nunes, W.A.G.A., Meurer, I., Souza Júnior, W.S. 2011. Produtividade e viabilidade econômica da cana-de-açúcar em diferentes sistemas de preparo do solo no Centro-oeste do Brasil. Revista de Ciências Agrárias, 34, 200-211.

Centurion, J.F., Freddi, O. Silva da., Aratani, R.G., Metzner, A.F.M., Beutler, A.N., Andriolo, I. 2007. Influência do cultivo da cana-de-açúcar e da mineralogia da fração argila nas propriedades físicas de Latossolos Vermelhos. Revista Brasileira de Ciência do Solo, 31, 199-209.

Fagundes, E.A.A., Silva, T.J.A., Silva, E.M.B. 2014. Desenvolvimento inicial de variedades de cana-de-açúcar em Latossolo submetidas a níveis de compactação do solo. Revista Brasileira de Engenharia Agrícola e Ambiental, 18, 188-193.

Guimarães, R.M.L., Blainski, E., Fidalski, J. 2013. Intervalo hídrico ótimo para avaliação da degradação física do solo. Revista Brasileira de Ciência do Solo, 37, 1512-1521.

Kamimura, K.M., Alves, M.C., Arf, O., Binotti, F.F.S. 2009. Propriedades físicas de um Latossolo Vermelho sob cultivo de arroz de terras altas em diferentes manejos do solo e água. Bragantia, 68, 723-731.

Laurindo, M.C.O., Nóbrega, L.H.P., Pereira, J.O., Melo, D. de., Laurindo, E.L. 2009. Atributos físicos do solo e teor de carbono orgânico em sistemas de plantio direto e cultivo mínimo. Engenharia na agricultura, 17, 367-374.

Marasca, I., Lemos, S.V., Silva, R.B., Guerra, S.P.S., Lanças, K.P. 2015. Soil Compaction Curve of an Oxisol under Sugarcane Planted after In-Row Deep Tillage. Revista Brasileira de Ciência do solo, 39, 1490-1497.

Oliveira, P. R., Centurion, J. F., Centurion, M. A. P. C., Franco, H. B. J., Pereira, F. S., Bárbaro Júnior, L. S., Rossetti, K. V. 2012. Qualidade física de um Latossolo Vermelho cultivado com soja submetido a níveis de compactação e de irrigação. Revista Brasileira de Ciência do solo, 36, 587-597.
Ralisch, R., Miranda, T.M., Okumura, R.S., Barbosa, G.M.C. de., Guimarães, M.F.; Scopel, E.; Balbino, E.S. 2008. Resistência à penetração de um Latossolo Vermelho Amarelo do Cerrado sob diferentes sistemas de manejo. Revista Brasileira de Engenharia Agrícola e Ambiental, 12, 381-384.

Rossetti, K. V., Centurion, J. F. 2013. Sistemas de manejo e atributos físico-hídricos de um Latossolo Vermelho cultivado com milho. 2013. Revista Brasileira de Engenharia Agrícola e Ambiental, 17, 472-479.

Sá, M.A.C., Santos Junior, J.D.G., Franz, C.A.B., Rein, T.A. 2016. Qualidade física do solo e produtividade da cana-deaçúcar com uso da escarificação entre linhas de plantio. Pesquisa Agropecuária Brasileira, 51, 1610-1622.

Silva, A.A., Castro, S.S. 2015. Indicadores macro e micromorfológicos da qualidade física de um Latossolo Vermelho cultivado com cana-de-açúcar. Mercator, 4, 3, pp. 169-185.

Souza, G.S., Souza, Z.M., Silva, R.B., Araújo, F.S., Barbosa, R.S. 2012. Compressibilidade do solo e sistema radicular da cana-de-açúcar em manejo com e sem controle de tráfego. Pesquisa Agropecuária Brasileira, 47, 603-612.

Valadão, F. C. A., Weber, O.L., Valadão Júnior, D.D. Scarpinelli, A., Deina, F. R., Bianchini, A. 2015. Adubação fosfatada e compactação do solo: sistema radicular da soja e do milho e atributos físicos do solo. Revista Brasileira de Ciência do Solo, 39, 243-255.

Viana, E.T., Batista, M.A., Tormena, C.A., Costa, A.C.S. da., Inoue, T.T. 2011. Atributos físicos e carbono orgânico em Latossolo Vermelho sob diferentes sistemas de uso e manejo. Revista Brasileira de Ciência do Solo, 35, 2105-2114.

Vischi Filho, O.J., Souza, Z.M., Silva, R.A., Lima, C.C., Pereira, D.M.G., Lima, M.E., Sousa, A.C.M., Souza, G.S. 2015. Capacidade de suporte de carga de Latossolo Vermelho cultivado com cana-de-açúcar e efeitos da mecanização no solo. Pesquisa Agropecuária Brasileira, 50, 322-332. 